\title{
Gaucher's Disease II. Studies on the Kinetics of $\beta$-Glucosidase and the Effects of Sodium Taurocholate in Normal and Gaucher Tissues
}

\author{
FRANCIS Y. M. CHOY AND RONALD G. DAVIDSON
}

Department of Pediatrics, McMaster University Medical Centre, Hamilton, Ontario, Canada

\begin{abstract}
Summary
$\beta$-glucosidase activity from normal human cultured fibroblasts was not affected by the presence of up to $0.1 \%(\mathrm{w} / \mathrm{v})(1.86 \mathrm{mM})$ purified sodium taurocholate. At concentrations greater than $0.1 \%$, there was a gradual decrease in activity. Conversely, $\beta$-glucosidase activity from fibroblasts of three patients with juvenile onset Gaucher's disease was preferentially inhibited by the detergent at concentrations as low as $0.025 \%(0.46 \mathrm{mM})$. A $40 \%$ decrease in activity was observed at $0.1 \%$. Crude sodium taurocholate was more potent in inhibiting $\beta$-glucosidase activity from both the normal and Gaucher fibroblasts. However, very high background fluorescence and inconsistent results were observed when different batches of the crude taurocholate from the same or different sources were used. Similarly, $\beta$-glucosidase activity from Gaucher splenic tissue homogenates, supernatant fluids $(40,000 \times \mathrm{g})$ and residue pellets was preferentially inhibited by purified sodium taurocholate. These findings indicate that the reliability and sensitivity of the enzyme assay for Gaucher's disease can be enhanced by determining $\beta$-glucosidase activity in both the absence and presence of purified sodium taurocholate, particularly when variant cases with relatively high residual enzyme activity are encountered. In contrast to the enzyme from fibroblasts and spleens, $\beta$-glucosidase activity from human placenta was markedly activated (> $300 \%)$ by the presence of $0.08 \%(1.49 \mathrm{mM})$ purified sodium taurocholate or $0.1 \mathrm{mM}$ phosphatidyl serine, suggesting the presence of a predominate form of $\beta$-glucosidase, possibly glucocerebroside $\beta$-glucosidase, which is activated by the detergent. The apparent Michaelis constant $(\mathrm{Km})$ for both the soluble and membranebound enzyme from normal fibroblasts was $1.6 \pm 0.1 \mathrm{mM}$. Kms from a patient with severe juvenile Gaucher's disease and two other patients with milder manifestations were $0.8 \pm 0.2$ and 3.3 $\pm 0.3 \mathrm{mM}$, respectively.
\end{abstract}

\section{Speculation}

The observation that $\beta$-glucosidase activity from tissues of patients with juvenile onset forms of Gaucher's disease is preferentially inhibited by the detergent, sodium taurocholate, suggests that a structurally altered- $\boldsymbol{\beta}$-glucosidase, which is more susceptible to inhibition by sodium taurocholate, is synthesized in patients with the disease. The severity of the disease could depend on the particular amino acid affected in the primary structure of the enzyme. An alternate explanation is the presence of at least two enzymes, which may or may not be isozymes, each capable of releasing glucose from the artificial fluorogenic substrate, but only one, which is deficient in Gaucher's disease, can hydrolyse the natural substrate and is unaffected by the presence of sodium taurocholate.

Glucocerebrosidase (glucosylceramidase, EC 3.2.1.45) is a lysosomal enzyme that cleaves the $\beta$-glucosidic bond of the glyco- sphingolipid, glucocerebroside. Deficient activity of this enzyme results in the accumulation of glucocerebroside (6), the characteristic feature of Gaucher's disease $(5,14,29)$. Deficiencies of $\beta$ glucosidase ( $\beta$-D-glucoside glucohydrolase, EC 3.2.1.21) have also been demonstrated in tissues of patients with Gaucher's disease when the fluorogenic substrate, 4-methylumbelliferyl- $\beta$-D-glucopyranoside (4 MUGP), is employed $(2,3,10,17,19,22,24,28)$. Although the $\beta$-glucosidase assay procedures for the diagnosis of Gaucher's disease had been well documented $(2,3,10,17,19,22$, $24,28)$, a recent report indicated that these methods were not easily reproducible (32). If, however, the detergents, sodium taurocholate and Triton X-100, were included in the leukocyte enzyme assay system, $\beta$-glucosidase activity was diminished but more consistent and reproducible results were obtained (32). In addition, sodium taurocholate had been reported to be essential for the extraction and enhancement of catalytic activity of $\beta$ glucosidase from human placenta $(11,26)$ and spleen $(15)$. This clearly demonstrated the variable tissue specificity of $\beta$-glucosidase; i.e., enzyme from different sources reacted differently with sodium taurocholate. Therefore, it seemed important to study the effects of sodium taurocholate on $\beta$-glucosidase from cultured human skin fibroblasts, a convenient source of enzyme for the diagnosis of Gaucher's disease as well as for biochemical studies in man. In addition, the recent report of an electrophoretic technique for the detection of $\beta$-glucosidase isozymes in human tissues had revealed concomitantly that $\beta$-glucosidase is a highly tissuespecific enzyme (10). In this report are the results of studies of the effect of sodium taurocholate on $\beta$-glucosidase activity from cultured skin fibroblasts as compared to that from the placenta and spleen, along with data that provide further support for the synthesis of a structurally altered enzyme in Gaucher's disease. These studies also provide useful information for the establishment of a more sensitive and reproducible assay method in the presence of this detergent for the diagnosis of Gaucher's disease. particularly when variant cases are encountered.

\section{MATERIALS AND METHODS}

Sodium taurocholate (grade A) was the product of Calbiochemicals, La Jolla, California. Crude sodium taurocholate, chemically synthesized ( $98 \%$ pure) sodium taurocholate, and phosphatidyl serine were the products of Sigma Chemical Co., St. Louis, Missouri. 4-Methylumbelliferone (4 MU) and 4 MUGP were obtained from Koch Light Labs Ltd., Coinbrook, Bucks, England.

All patients, except one, were of non-Jewish ancestry as far as is known. Patient 1 (Table 1) is half Jewish: his father is an Ashkenazi Jew; his mother, a non-Jewish Swede. Although the clinical manifestations were highly variable, none showed any sign of neurologic deterioration and all would, therefore, be classified as type I.

Skin fibroblasts were obtained from punch biopsies, cultured and harvested as previously described (10). Fibroblast homoge- 
nates were prepared by multiple freeze-thawing of the cell suspension in an ethylene glycol dry-ice bath consecutively for five times. Placentas were obtained after normal deliveries in the local obstetrical unit. Spleen and liver specimens were obtained at autopsy or biopsy. All tissues were stored at $-70^{\circ} \mathrm{C}$ until used. Homogenates and tissue extracts from these organs were prepared as previously described (10). Leukocytes were isolated from fresh human venous blood by a dextran gradient (1) and extracts were prepared in the same manner as for fibroblasts (10).

$\beta$-glucosidase was assayed at $37^{\circ} \mathrm{C}$ by adding $10 \mu \mathrm{l}$ of enzyme preparation, which contained $10-40 \mu \mathrm{g}$ protein, to a reaction mixture comprised of $70 \mu \mathrm{l}$ of $3.0 \mathrm{mM} 4 \mathrm{MUGP}, 15 \mu \mathrm{l}$ of $0.2 \mathrm{M}$ citrate buffer, $\mathrm{pH} 4.5$ or at other $\mathrm{pH}$, and $5 \mu \mathrm{l}$ of water or sodium taurocholate at various concentrations. Each assay tube contained the same amount of protein as enzyme source unless otherwise stated. The reaction mixture was incubated for 30-60 min, and the reaction was stopped by the addition of $1.5 \mathrm{ml} 0.2 \mathrm{M}$ glycine buffer, $\mathrm{pH}$ 10.5. 4 MU $\beta$-glucosidase activity was determined by the intensity of fluorescence emitted, as previously described (10).

For kinetic studies, varied amounts of 4 MUGP were included in the reaction mixture and the reaction was stopped after $30 \mathrm{~min}$ of incubation at $37^{\circ} \mathrm{C}$.

The effect of phospholipids on $\beta$-glucosidase activity was studied according to the method of Dale et al. (12). Protein was measured by the method of Lowry et al. (20).

\section{RESULTS}

$\beta$-glucosidase activity from cultured skin fibroblasts of three patients with juvenile onset Gaucher's disease and three normal controls is shown in Table 1 . Results of the $\beta$-glucosidase activity assays were observed to be consistent and reproducible from cells during their 4 th-19th passages. The inhibitory effects of crude and purified (grade A) sodium taurocholate on $\beta$-glucosidase from both normal and juvenile onset Gaucher fibroblast homogenates

Table 1. $\beta$-glucosidase activity in fibroblast homogenates from normal controls and patients with juvenile Gaucher's disease

\begin{tabular}{cclc}
\hline Normal control & Age & \multicolumn{1}{c}{ Sex } & $\beta$-glucosidase Clinical picture $^{1}$ \\
\hline 1 & 29 & Male & 189.9 \\
2 & 17 & Male & 164.4 \\
3 & 12 & Female & 176.0
\end{tabular}

Gaucher's dis-

ease

$\begin{array}{rrlrl}1 & 7 & \text { Female } & 42.0 & \text { Moderate } \\ 2 & 3 & \text { Male } & 15.2 & \text { Severe } \\ 3 & 16 & \text { Male } & 51.1 & \text { Moderate }\end{array}$

${ }^{1}$ Activity was expressed as the amount of $4 \mathrm{MU}$ (nanomoles) liberated/ $\mathrm{hr} / \mathrm{mg}$ protein. All assays were performed in duplicate that agreed within $5 \%$. are shown in Figure 1. In Gaucher fibroblasts, inhibition of $\beta$ glucosidase activity by sodium taurocholate was observed at concentrations as low as $0.025 \%(0.46 \mathrm{mM})$. This decrease in activity was proportional to the amount of sodium taurocholate in the reaction assay mixture. $\beta$-glucosidase activity in normal fibroblasts was not affected by the presence of sodium taurocholate at low concentrations. When purified sodium taurocholate was used (Fig. 1a), there was a gradual decrease in enzyme activity at concentrations higher than $0.1 \%(1.86 \mathrm{mM})$. Similar observations were noted when chemically synthesized sodium taurocholate was used. In addition, the crude sodium taurocholate was more potent in inhibiting $\beta$-glucosidase activity in both normal and Gaucher fibroblasts (Fig. 1b).

When the amounts of Gaucher fibroblast homogenates added to the enzyme assay mixture were increased so that $\beta$-glucosidase activity was equivalent to that of normal controls, similar preferential inhibition of $\beta$-glucosidase activity was observed.

Very high background fluorescence was noted in the crude bile salt. Thus, in calculating $\beta$-glucosidase activity in the presence of crude sodium taurocholate, care must be taken to subtract this background fluorescence. Otherwise, artificially high readings will result which appear to indicate enhancement of $\beta$-glucosidase activity. In addition, batches of crude taurocholate from different manufacturers gave results which were not comparable.

Because sodium taurocholate is the salt of a weak acid and strong base (taurocholic acid and sodium hydroxide), the $\mathrm{pH}$ of a $0.5 \%$ solution is 8.5 . In order to be certain that the decrease in $\beta$ glucosidase activity at higher concentrations of sodium taurocholate is not due to an elevation in the $\mathrm{pH}$ of the enzyme assay system above its optimum, the $\mathrm{pH}$ of the final substrate buffer reaction mixture was measured. There was no appreciable change in $\mathrm{pH}$ within the range of sodium taurocholate concentrations employed. The $\mathrm{pH}$ was 4.55 at $0.5 \%$ as compared to 4.50 at $0 \%$.

The effects of sodium taurocholate on $\beta$-glucosidase activity in normal and Gaucher spleens are shown in Table 2. As observed in the cultured fibroblasts, $\beta$-glucosidase from Gaucher spleens was preferentially inhibited by $0.5 \%(9.3 \mathrm{mM})$ sodium taurocholate. This phenomenon was observed in the crude tissue homogenates, in the supernatant after centrifugation at $40,000 \times g$ for 1 $\mathrm{hr}$, and in the residual pellet. In the residual pellet, $\beta$-glucosidase was slightly enhanced in the controls but markedly inhibited in the patients.

In contrast to the enzyme of fibroblasts and spleen, $\beta$-glucosidase activity from placental extracts was greatly activated by the presence of purified sodium taurocholate (Fig. 2). A $300 \%$ enhancement in activity was observed in the presence of $0.08 \%(0.46$ $\mathrm{mM}$ ) sodium taurocholate. In marked contrast, crude sodium taurocholate inhibited $\beta$-glucosidase activity. There was a gradual decrease in enzyme activity as the amount of crude sodium taurocholate in the assay mixture was increased (Fig. 2).

$\beta$-glucosidase from human placenta had been reported to be activated in the presence of various acidic phospholipids (12). Because $\beta$-glucosidase from the placenta was the only enzyme in

Table 2. $\beta$-glucosidase activity from normal and Gaucher spleens with and without purified sodium taurocholate (sod. tau.)

\begin{tabular}{|c|c|c|c|c|c|c|c|c|c|}
\hline & \multicolumn{3}{|c|}{ Homogenate } & \multicolumn{3}{|c|}{ Supernatant } & \multicolumn{3}{|c|}{ Residue pellet } \\
\hline & \multicolumn{3}{|c|}{$0.5 \%$ sod. } & \multicolumn{3}{|c|}{$0.5 \%$ sod. } & \multicolumn{3}{|c|}{$0.5 \%$ sod. } \\
\hline & No sod. tau. & tau. & $\%$ Inhibition & No sod. tau. & tau. & $\%$ Inhibition & No sod. tau & tau. & $\%$ Inhibition \\
\hline Normal controls & $8.9^{1}$ & 6.9 & 22.5 & 13.7 & 10.3 & 24.6 & 7.1 & 7.6 & 0 \\
\hline \multicolumn{10}{|l|}{ Gaucher's disease } \\
\hline 1 & 1.5 & 0.9 & 40.0 & 1.0 & 0.5 & 50.0 & 0.4 & 0.1 & 75 \\
\hline 2 & 2.7 & 1.8 & 33.3 & 4.4 & 1.1 & 75.0 & 0.9 & 0.3 & 66.7 \\
\hline 3 & 4.8 & 1.8 & 63.0 & 1.5 & 0.4 & 73.3 & 1.7 & 0.3 & 82.3 \\
\hline 4 & 5.6 & 1.2 & 79.0 & 8.8 & 0.8 & 91.0 & 1.8 & 0.2 & 88.9 \\
\hline 5 & 2.3 & 0.35 & 85.0 & 0.8 & 0.1 & 87.5 & 1.2 & 0.3 & 75.0 \\
\hline
\end{tabular}

${ }^{1}$ Activity was assayed at $\mathrm{pH} 5.5$ and expressed as nanomoles of $4 \mathrm{MU}$ liberated $/ \mathrm{hr} / \mathrm{mg}$ protein. The average from two normal spleens was used as a control. All assays were performed in duplicate that agreed within $10 \%$. 

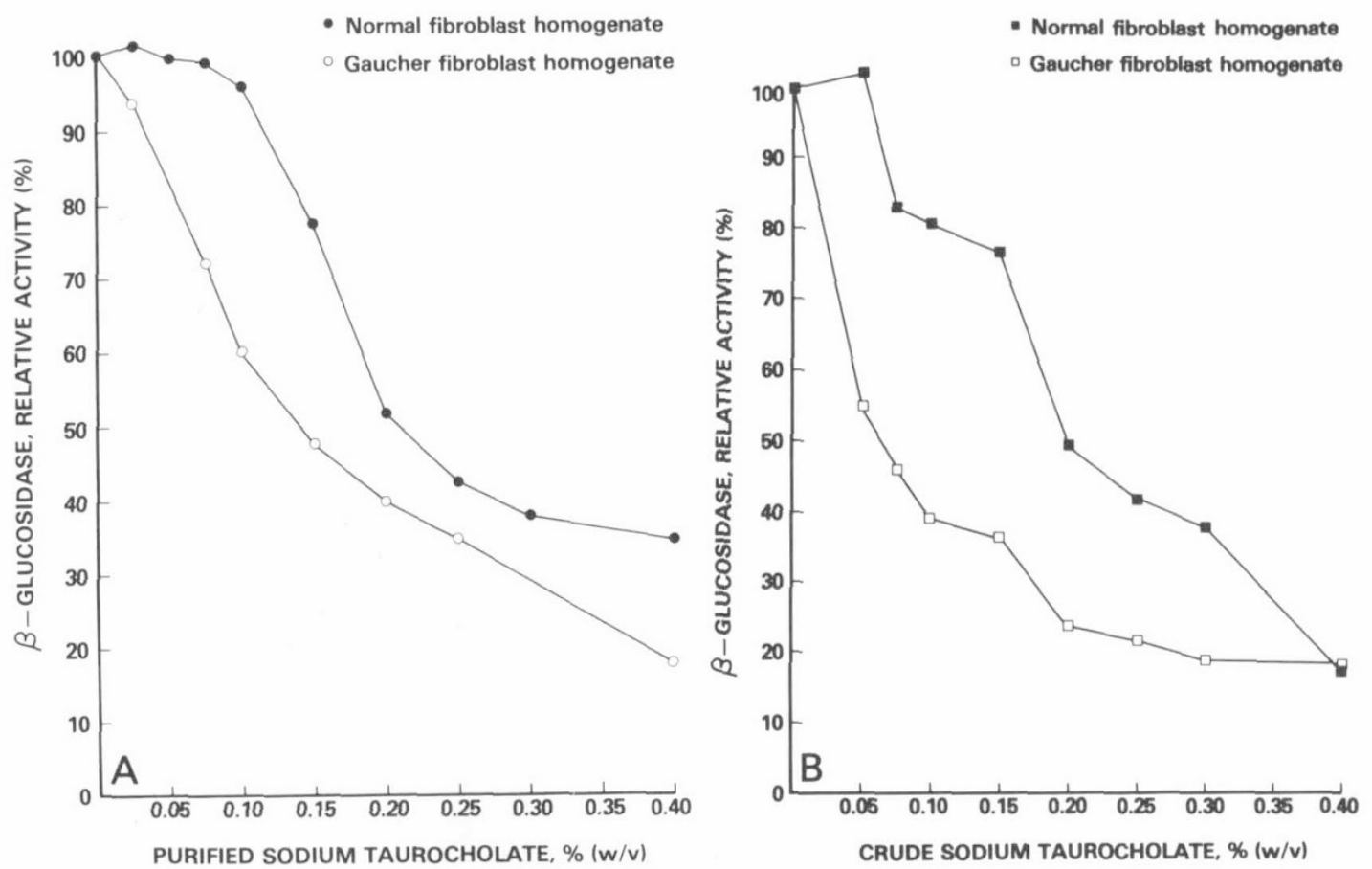

Fig. 1. $a$, The effect of purified sodium taurocholate on $\beta$-glucosidase activity from normal and Gaucher fibroblast homogenates. Cultured skin fibroblasts from patient 3 were used. Similar results were also observed from cultured skin fibroblasts of patients 1 and 2. $b$, The effect of crude sodium taurocholate on $\beta$-glucosidase activity from normal and Gaucher fibroblast homogenates.

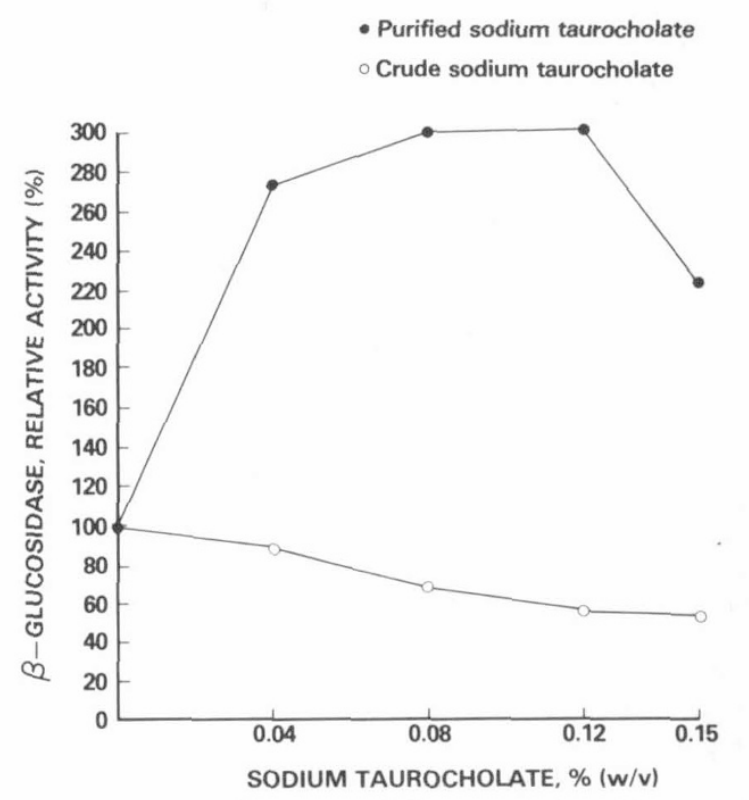

Fig. 2. The effect of sodium taurocholate on $\beta$-glucosidase activity from placental extracts.

these studies to be activated significantly by purified sodium taurocholate, the authors studied the effect of phosphatidyl serine, an acidic phospholipid, on $\beta$-glucosidase activity from various human tissues. As shown in Figure 3, when assayed in the presence of $0.1 \mathrm{mM}$ phosphatidyl serine, activities were severely diminished in crude liver extracts, in a 40 -fold partially purified liver preparation and in crude spleen extracts. Enzyme activity was moderately diminished in leukocyte extracts, but in the placenta $\beta$ glucosidase activity was dramatically increased (360\%) when assayed in the presence of this phospholipid.

Previous data suggested that synthesis of a structurally altered enzyme is the basic defect in Gaucher's disease (10). If this hypothesis is correct, $\beta$-glucosidase in patients with Gaucher's disease should possess different kinetic properties from the normal enzyme. In order to avoid the complication of mixed kinetics (13)
No phosphatidyl serine

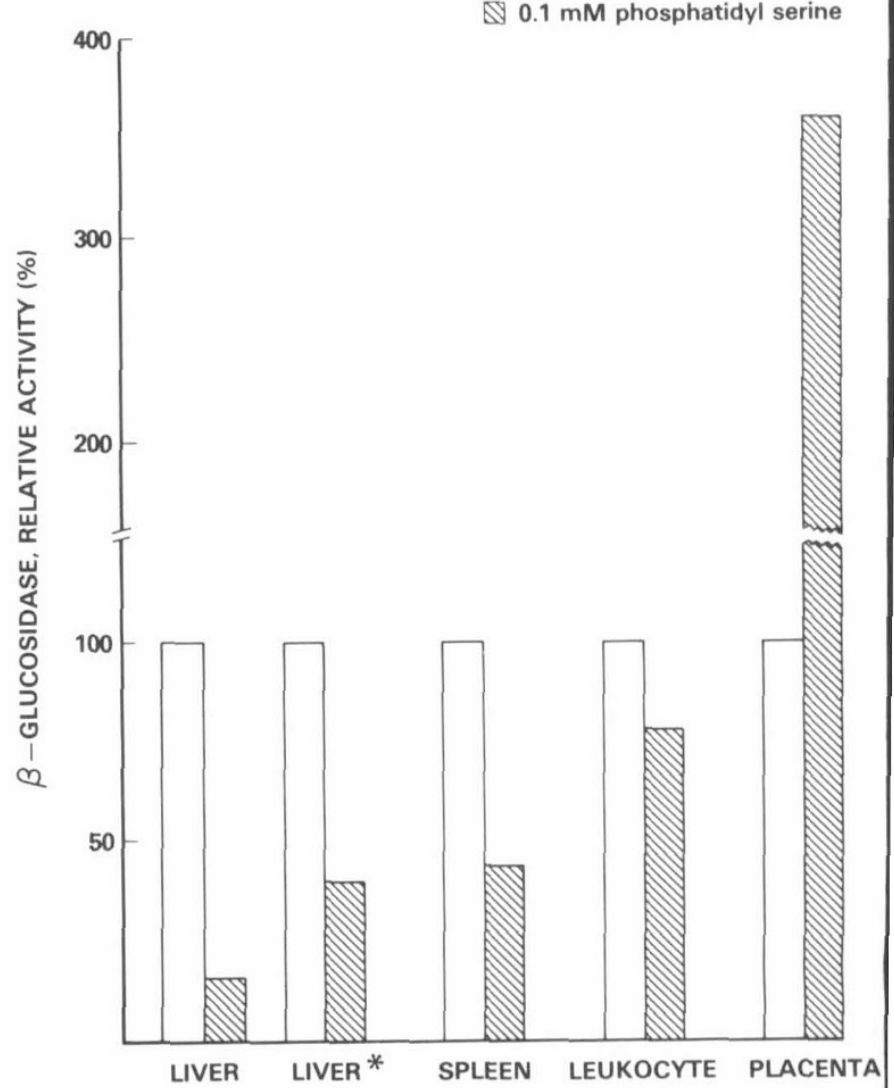

Fig. 3. The effect of phosphatidyl serine on $\beta$-glucosidase activity from various tissue extracts. ${ }^{*} \mathrm{~A} 40$-fold purified enzyme preparation from liver extract. The authors have recently purified $\beta$-glucosidase from human liver to homogeneity. The effect of sodium taurocholate and phosphatidy. serine on $\beta$-glucosidase activity changes from inhibiting to stimulating as the enzyme was progressively purified. A purified enzyme preparation had an absolute requirement for purified sodium taurocholate or phosphatidy. serine for its activity. 
when isozymes of $\beta$-glucosidase may be present in the assay system $(17)$, fibroblast homogenates (freeze-thawed $\times 10$ ) were centrifuged at $48,000 \times g$ for $1 \mathrm{hr}$ at $3^{\circ} \mathrm{C}$ to separate the membranebound form of the enzyme from the soluble enzyme in the supernatant. The pellet after centrifugation was resuspended and mixed thoroughly in 3 volumes of ice-chilled isotonic saline, centrifuged, and resuspended in saline. This procedure was repeated until no further soluble $\beta$-glucosidase could be detected in the $48,000 \times g$ supernatant. Kinetic properties of $\beta$-glucosidase in the supernatant (soluble enzyme) and pellet (membrane-bound enzyme) were then determined and the results are shown in Figure 4. The apparent Michaelis constant for both the soluble and membrane-bound enzyme was $1.6 \pm 0.1 \mathrm{mM}$. Additionally, when $0.12 \%$ crude sodium taurocholate was included in the assay system for membrane-bound $\beta$-glucosidase, a noncompetitive type of inhibition was observed.

Very different kinetics were observed with the membranebound $\beta$-glucosidase from the fibroblasts of three patients with juvenile Gaucher's disease (Fig. 5). As well as having much lower Vmax values, the apparent Michaelis constants were very different from each other and from the normal controls. The $\mathrm{Km}$ of membrane-bound $\beta$-glucosidase from three normal controls was $1.6 \pm 0.1 \mathrm{mM}$. Kms from a patient with severe juvenile Gaucher's disease and two other patients with milder manifestations were $0.8 \pm 0.2 \mathrm{mM}$ and $3.3 \pm 0.3 \mathrm{mM}$, respectively.

During the course of these studies, a 4-yr-old boy with splenomegaly and mild hypersplenism was seen. The possibility of Gaucher's disease was raised. $\beta$-glucosidase activity assayed from his leukocytes was $25 \%$ of normal, but enzyme activity from his fultured fibroblasts assayed in the absence of sodium taurocholate vas within the lower limit of normal range (Fig. 6). However, when sodium taurocholate was added to the assay system, $\beta$ lucosidase activity was dramatically decreased. The diagnosis of Gaucher's disease was further confirmed by the abnormal electrophoretic pattern of $\beta$-glucosidase from his leukocyte extracts (10).

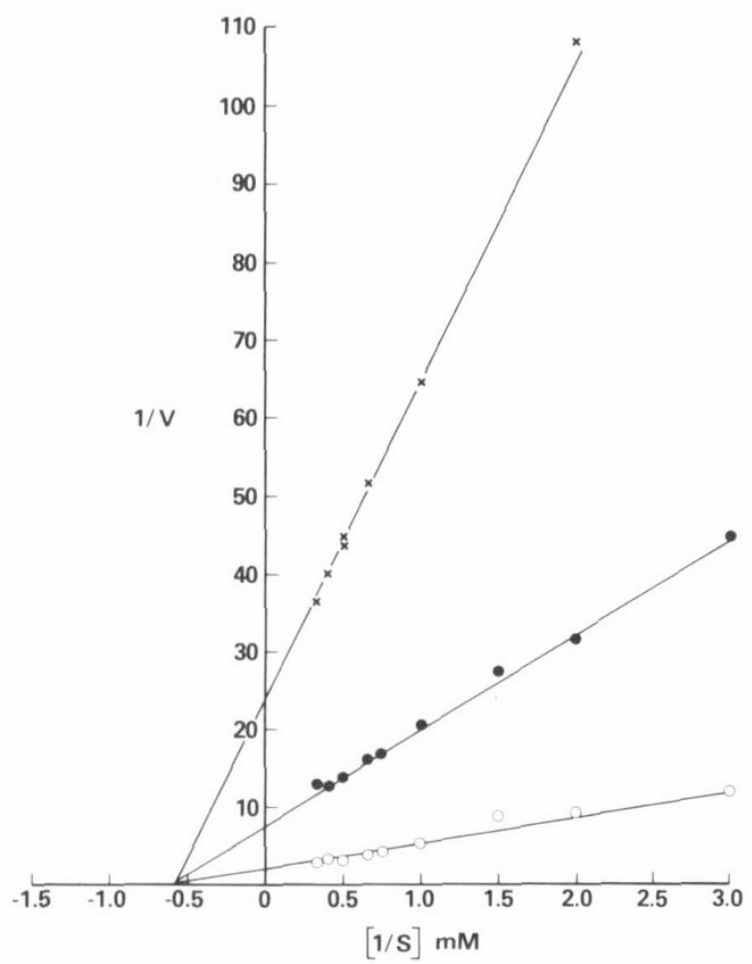

Fig. 4. Linweaver-Burk plot of $\beta$-glucosidase activity from normal litured skin fibroblasts. $\mathrm{V}$ is expressed as $4 \mathrm{MU}$ (millimoles) liberated/ $\mathrm{r} / \mathrm{mg}$ protein. $\bigcirc$ : enzyme activity in $48,000 \times \mathrm{g}$ pellet; $\boldsymbol{\bullet}$, enzyme activity $48,000 \times g$ supernatant fluid; $x$, enzyme activity in $48,000 \times g$ pellet in te presence of $0.12 \%$ crude sodium taurocholate.

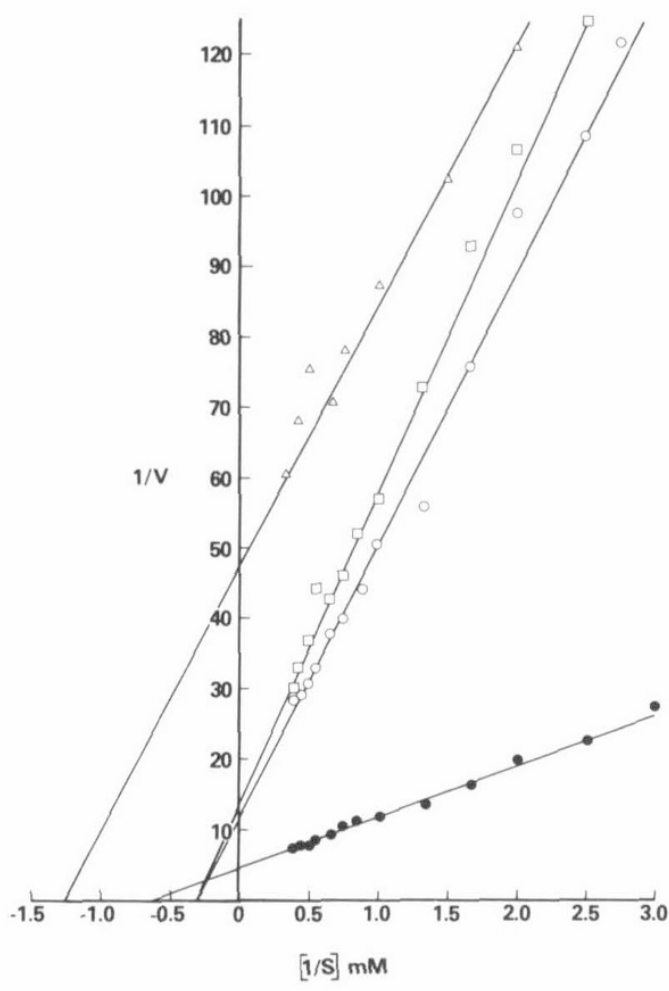

Fig. 5. Linweaver-Burk plot of membrane-bound $\beta$-glucosidase from cultured skin fibroblasts. : normal control; $\square, \Delta, \bigcirc$, Gaucher's disease (Table 1, Patients 1, 2, and 3, respectively). V is expressed as $4 \mathrm{MU}$ (millimoles) liberated $/ \mathrm{hr} / \mathrm{mg}$ protein.

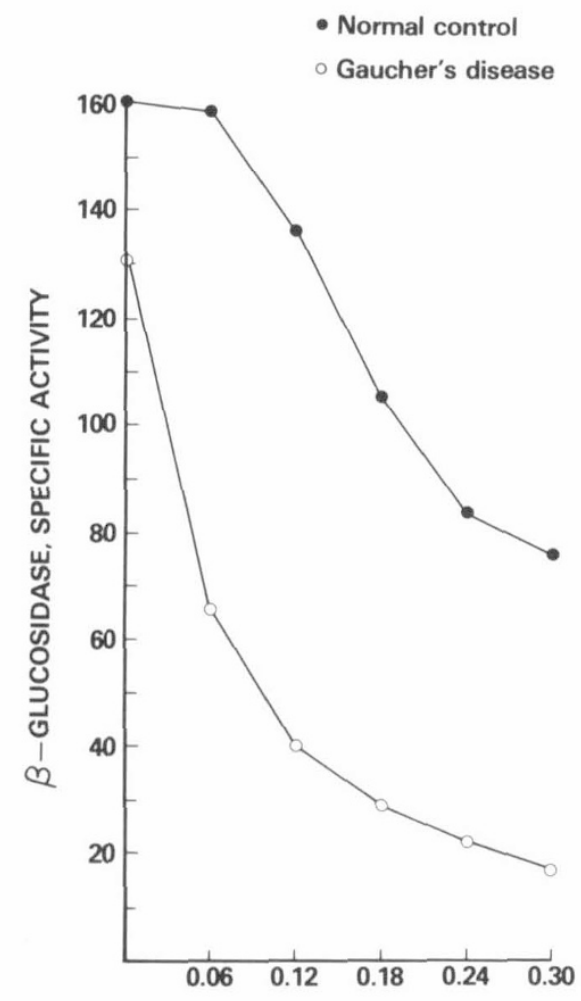

SODIUM TAUROCHOLATE, \% (w/v)

Fig. 6. The effect of purified sodium taurocholate on $\beta$-glucosidase activity from a normal individual and a patient with Gaucher's disease. Specific activity is expressed as nanomoles of $4 \mathrm{MU}$ liberated $/ \mathrm{hr} / \mathrm{mg}$ protein. 


\section{DISCUSSION}

Sodium taurocholate had been shown to stimulate and stabilize $\beta$-glucocerebrosidase activity from the spleen (15) and the placenta $(11,12,26)$, and has become a standard component of the assay system. However, the effect of the purified bile salt on $\beta$-glucosidase activity from cultured skin fibroblasts and peripheral blood leukocytes when the fluorogenic substrate, 4 MUGP, is used for the diagnosis of Gaucher's disease $(2,3,17,19,28)$ has not been described. Sodium taurocholate from different commercially available sources may also result in very different findings depending on the purity of the product. In this paper, the authors have studied the effect of sodium taurocholate from various sources on $\beta$-glucosidase activities in different human tissues and established a sensitive assay procedure for the diagnosis of Gaucher's disease using the fluorogenic substrate, 4 MUGP. The finding that $\beta$-glucosidase from Gaucher fibroblasts is more susceptible to inhibition by crude or purified taurocholate than the normal enzyme can be applied to enhance the sensitivity of the assay system, especially when variant cases are encountered (Fig. 6 ). Because of the heterogeneity and complexity of this metabolic disorder, wherein tissues from patients with Gaucher's disease may have $\beta$-glucosidase deficiency $(8,18,22)$, multiple glycosidase deficiencies (9), or normal levels of enzyme activity (7, 16, 23) towards artificial $\beta$-glucoside substrates, enzyme assay for the diagnosis of Gaucher's disease using the fluorogenic substrate 4 MUGP should be performed in both the absence and presence of purified sodium taurocholate.

If the basic enzymatic defect in Gaucher fibroblasts were a deficient amount of structurally normal $\beta$-glucosidase, then the amount of enzyme added to the reaction mixture would be less than that in the normal controls. In that case, the apparent preferential inhibition of $\beta$-glucosidase activity from Gaucher fibroblasts by excess sodium taurocholate would simply be an artefact resulting from that excess. In order to eliminate that possibility, the amount of fibroblast homogenate from patient 3 (whose $\beta$-glucosidase activity level is approximately one-third of normal, as shown in Table 1) was tripled in the enzyme assay. The preferential inhibition of $\beta$-glucosidase activity by the detergent remained. This same phenomenon was also observed in fibroblasts of two other patients with juvenile Gaucher's disease (Table 1, patients 1 and 2).

Similar effects of sodium taurocholate on $\beta$-glucosidase activity were observed in the homogenates, supernatant and residual fractions of the two control and five Gaucher spleens in that $\beta$ glucosidase from the Gaucher spleens appeared to be more susceptible to inhibition by this bile salt. This observation was in accordance with findings of Peters et al. (27) who reported an $80 \%$ inhibition of $\beta$-glucosidase in Gaucher splenic homogenates in the presence of $0.6 \%$ sodium taurocholate. Based on this and other studies of the human liver, they concluded that human tissue contains at least two enzymes capable of releasing glucose from 4 MUGP, but only one of these enzymes can hydrolyse glucocerebroside; the latter is deficient in individuals with Gaucher's disease. This may partially explain the preferential inhibitory effect of sodium taurocholate on $\beta$-glucosidase in Gaucher tissues. The nonspecific $\beta$-glucosidase present in patients with Gaucher's disease is selectively inhibited, whereas the glucocerebrosidase deficient in Gaucher's disease is stimulated in normal tissues. The distribution of these two $\beta$-glucosidases varies in different tissues. In the placenta, glucocerebrosidase is presumably the predominant form, as more than a $300 \%$ increase in $\beta$-glucosidase activity was observed in the presence of purified sodium taurocholate (Fig. 2). Similarly, phosphatidyl serine may play the same role by inhibiting the nonspecific $\beta$-glucosidase activity and stimulating glucocerebrosidase activity (Fig. 3 ).

The findings that purified sodium taurocholate should be used exclusively in the diagnosis of Gaucher's disease using the fluorogenic substrate is in accordance with a recent report by Wenger et al. (32). Crude sodium taurocholate was observed to interfere with the assay of $\beta$-glucosidase activity from leukocytes and to create high background fluorescence (32). Purified sodium taurocholate from Calbiochemicals, as employed in these experiments, was recommended (32).

The results of kinetic studies with membrane-bound $\beta$-glucosidase from fibroblasts support our previous suggestion that the synthesis of a genetically altered enzyme, rather than a quantitative deficiency of normal enzyme, exists in Gaucher's disease. Of note is the observation that the apparent Michaelis constants $(\mathrm{Km})$ of $\beta$-glucosidase from different Gaucher fibroblasts are different from each other in addition to being different substantially from that of the normal tissue, depending on the severity of the disease. As these assays are always performed in the presence of a normal control whose $\beta$-glucosidase $\mathrm{Km}$ value is always reproducible (1.6 $\pm 0.1 \mathrm{mM})$, it is not likely that experimental errors account for the difference in $\mathrm{Km}$ values from different patients with Gaucher's disease. In view of these findings, each case of Gaucher's disease may be the result of a mutation in the gene responsible for specifying the structure of $\beta$-glucosidase. The severity of Gaucher's disease could depend on the amino acid affected as a result of the mutation in the primary structure of the enzyme protein molecule, especially if it involves the catalytic site, which will profoundly affect the specificity and affinity of the substrate-enzyme binding, as well as the enzyme catalytic ability to convert the substrates into its products.

Recently, glucocerebrosidase was purified from spleens of normal humans and patients with Gaucher's disease by Pentchev et al. (25). Data from their studies on the substrate affinity, heat lability, pH optimum, sodium dodecyl sulfate gel electrophoresis and immunotitration (with glucocerebrosidase antiserum) of the two enzymes strongly suggest that the genetic basis of Gaucher's disease is a mutation of glucocerebrosidase which results in the synthesis of a structurally altered and catalytically deficient enzyme (25). Data from the previous (10) and present studies, as well as from Turner and Hirschhorn (31), support this hypothesis.

In two previous studies $(21,31)$ which used Triton $\mathrm{X}-100$ and sodium taurocholate-treated fibroblast homogenates or extracts from normal individuals and patients with juvenile and adul onset Gaucher's disease, residual $\beta$-glucosidase activities in the lipidotic cells were found to have increased heat lability, but could not be distinguished from that in normal cells with respect to ge exclusion properties (21), Michaelis constant $(21,31)$, and $\mathrm{pH}$ dependence (21). The apparent discrepancy between their result and the present finding of a genetically altered enzyme with different Michaelis constants in fibroblasts could have resulted from the different ethnic origins of the patients, theirs bein predominantly Ashkenazi Jewish (31) and these non-Jewish. Per haps a more likely explanation emerges from a comparison o methods. In our kinetic studies, both the membrane-bound $\beta$ glucosidase preparation and the assay system did not contain any detergent, whereas Triton X-100 and sodium taurocholate wer used in their enzyme preparation and assay system $(21,31)$. recent report by Turner et al. (30) had shown that $\beta$-glucosidas solubilized by Triton X-100 and sodium taurocholate did no exhibit the cell-specific differences in $\mathrm{pH}$ optimum and $\mathrm{Km}$ showr by the membrane-bound enzyme. They also suggested that $\beta$ glucosidase found in the Gaucher fibroblast represents a geneti cally altered form of the "acid-stable" $\beta$-glucosidase found ir normal cells (30), which is the result of a genetic mutation at th structural gene locus (31). This may explain why the mutate enzyme in Gaucher fibroblasts is more susceptible to heat inacti vation $(21,31)$ and to inhibition by sodium taurocholate.

\section{REFERENCES AND NOTES}

1. Avila, J. L., and Convit, J.: Studies on human polymorphonuclear leukocyt enzymes. I. Assay of acid hydrolases and other enzymes. Biochim. Biophys Acta, 293: 397 (1973).

2. Beutler, E., and Kuhl, W.: The diagnosis of the adult type of Gaucher's diseas and its carrier state in peripheral blood leukocytes. J. Lab. Clin. Med., 76: 74. (1970).

3. Beutler, E., Kuhl, W., Trinidad, F., Teplitz, R., and Nadler, H.: $\beta$-glucosidas activity in fibroblasts from homozygotes and heterozygotes for Gaucher disease. Am. J. Hum. Genet., 23: 62 (1971). 
4. Blonder, E., Klibansky, C., and DeVries, A.: Effects of detergents and cholinecontaining phospholipids on human spleen glucocerebrosidase. Biochim. Biophys. Acta, 431: 45 (1976)

5. Brady, R. O.: In: Stanburg, J. B., Wyngaarden, B., and Frederickson, D. S. Metabolic Basis of Inherited Disease. 4th Edition, (McGraw-Hill, New York, 1978) pp. 731-746.

6. Brady, R. O., Kanfer, J. N., and Shapiro, D.: Metabolism of glucocerebrosidase II. Evidence of enzymatic deficiency in Gaucher's disease. Biochim. Biophys. Acta, 18: 221 (1965)

7. Broadhead, D. M., and Butterworth, J.: The diagnosis of Gaucher's disease in liver using 4-methyumbelliferyl- $\beta$-D-glucopyranoside. Clin. Chim. Acta, 74: 155 (1977).

8. Chester, M. A., Hultberg, B., and Ockerman, P. A.: The common identity of five glucosidase in human liver. Biochim. Biophys. Acta, 429: 179 (1976).

9. Chiao, Y. B., Hoyson, G. M., Peters, S. P., Lee, R. E., Diven, W., Murphy, J. V., and Glew, R. H.: Multiple glycosidase deficiencies in a case of juvenile (type 3) Gaucher disease. Proc. Natl. Acad. Sci. USA, 75: 2448 (1978).

10. Choy, F. Y. M., and Davidson, R. G.: Gaucher's disease. I. Solublization and electrophoresis of $\beta$-glucosidase from human peripheral blood leukocytes and cultured skin fibroblasts. Pediatr. Res., 12: 1115 (1978).

11. Dale, G. L., and Beutler, E.: Enzyme replacement therapy in Gaucher's disease: "A rapid high-yield method for purification of glucocerebrosidase." Proc. Natl. Acad. Sci., USA, 73: 4672 (1976).

12. Dale, G. L., Villcaorte, D. G., and Beutler, E.: Solublization of glucocerebrosidase for human placenta and demonstration of a phospholipid requirement for its catalytic activity. Biochem. Biophys. Res. Commun., 71: 1048 (1976).

. Dixon, M. and Webb, E. C. In: Enzymes, 2nd Ed., (Academic Press, New York, 1964) p. 84.

4. Halliday, N., Denel, H. G., Jr., Tragerman, L. J., and Ward, W. E.: On the isolation of a glucose-containing cerebroside from spleen in a case of Gaucher's disease. J. Biol. Chem., 132: 171 (1940).

5. Ho, M. W.: Identity of "acid" $\beta$-glucosidase and glucocerebrosidase in human spleen. Biochem. J., 136: 721 (1973).

. Ho, M. W., and O'Brien, J. S.: Gaucher's disease: deficiency of acid $\beta$-glucosidase and reconstitution of enzyme activity in vitro. Proc. Natl. Acad. Sci., USA., 68: 2810 (1971).

17. Ho, M. W., Seck, J., Schmidt, D., Veath, M. L., Johnson, W., Brady, R. O., and O'Brien, J. S.: Adult Gaucher's disease: kindred studies and demonstration of a deficiency of acid $\beta$-glucosidase in cultured fibroblasts. Am. J. Hum. Genet., 24: 37 (1972).

. Kanfer, J. N., Raghavan, S. S., Mumford, R. A., Labow, R. S., Williamson, D. G., and Layne, D. S.: Deficiency of steroid $\beta$-glucosidase in Gaucher disease. Biochem. Biophys. Res. Commun., 67: 683 (1975).

9. Klibansky, G. H., Hofaan, J., Zaiaov, R., and Matoth, Y.: A comparative study of glucocerebroside and methylumbelliferylglucopyranoside cleaving potency in leukocytes. Biomedecine, 20: 24 (1974).
20. Lowry, D. H., Rosenbrough, N. J., Farr, A. L., and Randall, R. J.: Protein measurement with the folin phenol reagent. J. Biol. Chem., 193: 265 (1951).

21. Mueller, O. T., and Rosenberg, A.: $\beta$-glucosidase hydrolase activity of normal and glucosylceramidotic cultured human skin fibroblasts. J. Biol. Chem., 252: 825 (1976).

22. Ockerman, P. A.: Identity of $\beta$-glucosidase, $\beta$-xylosidase and one of the $\beta$ galactosidase activity in human liver when assayed with 4-methylumbelliferyl $\beta$-D-glycosides: studies in cases of Gaucher's disease. Biochim. Biophys. Acta, 165: 59 (1968).

23., Owada, M., Sakiyama, T., and Kitogawa, T.: Neuropathic Gaucher's disease with normal 4-methylumbelliferyl- $\beta$-glucosidase activity in the liver. Pediatr. Res.,, 11: 641 (1977).

24. Patrick, D. A.: A deficiency of glucocerebrosidase in Gaucher's disease. Biochem. J., 97: 17c (1965).

25. Pentchev, P. G., Brady, R. O., Blair, H. E., Britton, D. E., and Sorrell, S. H. Gaucher disease: isolation and comparison of normal and mutant glucocerebrosidase from human spleen tissue. Proc. Natl. Acad. Sci. USA, 75: 3970 (1978).

26., Pentchev, P. G., Brady, R. O., Hibbert, S. P., Gal, A. E., and Shapiro, C.: Isolation and characterization of glucocerebrosidase from human placental tissue. J. Biol. Chem., 348: 5256 (1973).

27. Peters, S. P., Coyle, P., and Glew, R. H.: Differentiation of $\beta$-glucocerebrosidase from $\beta$-glucosidase in human tissues using sodium taurocholate. Arch. Biochem. Biophys., 175: 569 (1976).

28. Peters, S. P., Lee, R. T., and Glew, R. H.: A microassay for Gaucher's disease Clin. Chim. Acta, 60:391 (1975).

29. Rosenberg, A., and Chargaff, E.: A reinvestigation of the cerebroside deposited in Gaucher's disease. J. Biol. Chem., 233: 1323 (1956).

30. Turner, B. M., Beratis, N. G., and Hirschhorn, K.: Cell-specific differences in membrane $\beta$-glucosidase from normal and Gaucher cells. Biochim. Biophys. Acta, 480: 422 (1977).

31. Turner, B. M., and Hirschhorn, K.: Properties of $\beta$-glucosidase in cultured skin fibroblasts from controls and patients with Gaucher's disease. Am. J. Hum. Genet., 30: 346 (1978).

32. Wenger, D. A., Clark, C., Sattler, M., and Wharton, C.: Synthetı substrates $\beta$-glucosidase activity in leukocyte: a reproducible method for the identification of patients and carrier of Gaucher's disease. Clin. Genet., 13: 145 (1978).

33. Dr.F. Y. M. Choy is the recipient of a Research Fellowship from the Ontario Mental Health Foundation, Canada.

34. This research was supported in part, by a grant from the Medical Research Council of Canada, MA-5789.

35. Requests for reprints should be addressed to: Dr. F. Y. M. Choy, McMaster University Medical Centre, Department of Pediatrics, Room 3N17, 1200 Main Street West, Hamilton, Ontario, Canada, L8S 4J9.

36. Received for publication November 15, 1978.

37. Accepted for publication January 30, 1979. 